\title{
Effects of oviductal fluid on the development, quality, and gene expression of porcine blastocysts produced in vitro
}

\author{
Rhiannon E Lloyd, Raquel Romar ${ }^{1}$, Carmen Matás ${ }^{1}$, Alfonso Gutiérrez-Adán², William V Holt \\ and Pilar Coy ${ }^{1}$
}

Institute of Zoology, Zoological Society of London, Regent's Park, London NW1 4RY, UK, ${ }^{1}$ Department of Physiology, Faculty of Veterinary, University of Murcia, Murcia 30071, Spain and ${ }^{2}$ Department of Animal Reproduction and Zoogenetic Resources Conservation, INIA, Ctra. de la Coruña Km 5.9, Madrid 28040, Spain

Correspondence should be addressed to P Coy who is now at Departamento de Fisiología, Facultad de Veterinaria, Universidad de Murcia, Murcia 30071, Spain; Email: pcoy@um.es

\begin{abstract}
In mammals, fertilization and early pre-implantation development occur in the oviduct. Previous results obtained in our laboratory have identified specific molecules in the oviduct that affect porcine sperm-egg interactions. The aim of the present study was to determine whether the contact between oocytes and oviductal fluid also affect embryo development, quality, and gene expression. In vitro matured porcine oocytes were exposed to bovine oviductal fluid (bOF) for $\mathbf{3 0}$ min prior to fertilization. Cleavage and blastocyst development rates were significantly higher from bOF-treated oocytes than from untreated oocytes. Blastocysts obtained from bOF-treated oocytes had significantly greater total cell numbers than those obtained from untreated oocytes. Using real-time PCR, grade 1 (very good morphological quality) and grade 2 (good morphological quality) blastocysts were analyzed for gene transcripts related to apoptosis (BAX, BCL2L1), mitochondrial DNA (mtDNA) transcription/replication (POLG, POLG2, and TFAM), blastomere connection and morula compaction (GJA1), and blastocyst formation and pluripotency (POU5F1). We found that the entire set of genes analyzed was differentially expressed between grade 1 and 2 blastocysts. Furthermore, bOF treatment reduced the ratio of $B A X$ to $B C L 2 L 1$ transcripts and enhanced the abundance of TFAM transcripts in grade 2 blastocysts. Not only do these findings demonstrate that factors within the bOF act on porcine oocytes both quickly and positively, but they also suggest that such factors could promote embryo development and quality by protecting them against adverse impacts on mtDNA transcription/replication and apoptosis induced by the culture environment.
\end{abstract}

Reproduction (2009) 137 679-687

\section{Introduction}

Recent studies have shown that the oviductal fluid (OF), the physiological milieu in which gametes meet, affects the biology of the oocyte by changing the resistance of the zona pellucida (ZP) to proteolysis. This change is mediated by the oviduct-specific glycoprotein (OVGP1), which modifies the sperm-egg interaction by binding to the ZP and, as a result, increases the levels of monospermy. Moreover, bovine oviductal fluid (bOF) produces a similar, but steadier, effect to the homologous fluid in pig (Coy et al. 2008a). Additionally, it has been shown that co-culturing embryos with oviductal cells or in vivo culture of embryos in oviducts of recipient animals increase the success of development following IVF (Rizos et al. 2002, Xu et al. 2004). These two observations indicate that the oviductal environment, and probably the OF, contains important molecules that affect the sperm-oocyte interaction and the subsequent developmental competence of zygotes.
Interestingly, other studies in pigs, mice, and humans have shown that supplementing culture media with oviductal proteins, such as OVGP1 (Kouba et al. 2000, McCauley et al. 2003) and a derivative of the complement component 3 (C3), iC3b, increases the number of in vitro embryos generated (Lee et al. 2004). However, the mechanism by which these proteins affect embryo development or whether other factors in the OF, apart from OVGP1 or iC3b, have an embryotrophic effect remain under study. Using such proteins or factors in a culture system might be a less complex, and therefore a more attractive alternative to embryo co-culture with somatic cells.

Previous experiments in our laboratory have shown that co-incubating porcine oocytes with bOF for a short period (30 min), after in vitro maturation (IVM) but prior to IVF, produces beneficial effects on fertilization outcomes by reducing polyspermy (Coy et al. 2008a). In these experiments, sperm and oocytes were co-incubated for a period of $18 \mathrm{~h}$ following bOF treatment 
of the oocytes. The aim of the present study was to determine whether the same short exposure of oocytes to bOF prior to fertilization, followed by a shorter (15 min) sperm-oocyte co-incubation, would also affect subsequent pre-implantation embryo development rates. It was hoped that a shorter sperm-oocyte co-incubation period would allow the effect of bOF on embryo development to be ascertained in the absence of any effect on polyspermy, as the percentage of polyspermic embryos is known to increase with increasing spermoocyte co-incubation time (Coy et al. 1993).

IVF and embryo culture have a profound effect on the pattern of gene expression in mouse blastocysts (Giritharan et al. 2007). IVF embryos differ from in vitro cultured (IVC) embryos in the expression of 3058 genes and the principal pathways concerned are cell proliferation, apoptosis, and morphogenetics. Also, the changes in gene expression observed in IVC embryos are thought to predispose them to certain diseases (Lonergan et al. 2003, Fernandez-Gonzalez et al. 2004, Lee \& Yeung 2006). As a second objective, we also wanted to determine whether the bOF treatment of porcine oocytes influences blastocyst quality. Total cell number and the transcript abundance of seven genes were assessed. Specifically, we wanted to determine the transcript abundance of four genes that have previously been shown to be differentially expressed between in vivo and in vitro blastocysts, and are therefore considered as markers of blastocyst quality in the bovine: BCL2associated $X$ protein ( $B A X$; pro-apoptotic; Rizos et al. 2002, Gutierrez-Adan et al. 2004, Rho et al. 2007), BCL2-like 1 (BCL21; anti-apoptotic; Rho et al. 2007), gap junction protein, alpha 1, $43 \mathrm{kDa}(G J A 1$; involved in the formation of gap junctions for cell-cell communication during pre-implantation development; De Sousa et al. 1997, Rizos et al. 2002, Gutierrez-Adan et al. 2004), and POU class 5 homeobox 1 (POU5F1; essential for peri-implantation development and embryonic cell pluripotency; Boiani et al. 2003, Rizos et al. 2007). The transcript abundance of three additional genes was also compared between blastocysts obtained from bOFtreated and untreated oocytes, namely mitochondrial polymerase gamma $(P O L G)$, mitochondria polymerase gamma 2 accessory subunit (POLG2), and mitochondrial transcription factor A (TFAM). These nuclear genes encode factors essential for the transcription and replication of mitochondrial DNA (mtDNA) and when either Polg or Tfam gene expression is disrupted, e.g. in mouse embryos where these genes have been knocked out, embryonic lethality ensues soon after implantation (Gray \& Wong 1992, Larsson et al. 1998, Hance et al. 2005). As a result of these observations, we also wondered whether the expression of such mtDNA transcription/replication factor genes could also serve as markers of quality in the blastocysts and be differentially expressed between blastocysts obtained from bOF-treated and untreated oocytes.
Our observations show that exposing porcine oocytes to bOF for a short time $(30 \mathrm{~min})$, in the absence of any effect on polyspermy, not only increases the percentage of cleaved embryos and the percentage of blastocysts formed, but also enhances the total cell number in blastocysts. Moreover, grade 2 blastocysts (classified according to the IETS manual, Robertson \& Nelson 1998) obtained from bOF-treated oocytes had greater TFAM transcript abundance and a clear anti-apoptotic gene expression profile, as defined by a reduced ratio of $B A X$ to $B C L 2 L 1$ transcripts, compared with the grade 2 blastocysts obtained from untreated oocytes.

\section{Results}

\section{Labeling of porcine ZP with the bovine anti-OVGP1}

After bOF treatment, immunocytochemical analysis revealed that bovine OVGP1 was found associated with the ZP of the porcine oocytes (Fig. 1).

\section{bOF increases the output for in vitro production of porcine blastocysts}

The percentages of penetration and monospermy in both groups of oocytes (pre-incubated with or without bOF) were similar. These results differ to those obtained in this laboratory previously under different experimental conditions, which showed that bOF-treated oocytes, when co-incubated with sperm for $18 \mathrm{~h}$ post-insemination, had a higher percentage of monospermy compared with untreated oocytes (Coy et al. 2008a; Supplementary Tables 1 and 2, which can be viewed online at www.reproduction-online.org/supplemental/). This result demonstrates that, in the present study, the experimental design we chose (15 min of co-incubation time) was effective to guarantee that any effects of bOF treatment on subsequent embryo development rates were not a result of differences in penetration and monospermy. From Supplementary Table 2, it can be observed that the final efficiency of the IVF system (calculated approximately as the percentage of penetrated oocytes
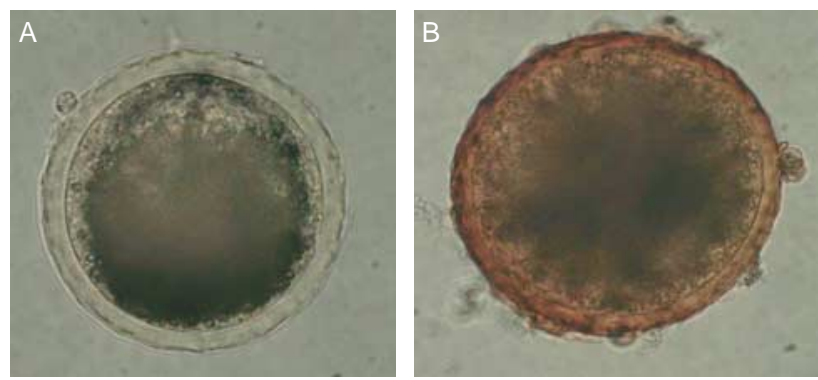

Figure 1 Binding of bovine OVGP1 to porcine ZP was detected immunocytochemically. (A) Porcine oocyte incubated with rabbit antiOVGP1 + anti-rabbit HRP showed a transparent non-stained ZP. (B) Porcine oocyte incubated $30 \mathrm{~min}$ in bovine oviductal fluid + rabbit anti-OVGP1 + anti-rabbit HRP showed a labelled ZP. 
multiplied by the percentage of monospermic oocytes divided by 100) was 39 and $35.5 \%$ respectively, for control and bOF-treated groups.

The percentage of cleaved embryos at $48 \mathrm{hpi}$ obtained from oocytes pre-incubated for 30 min with bOF was around $10 \%$ higher than from untreated oocytes $(P<0.05$; Table 1$)$. The percentage of blastocysts obtained from bOF-treated oocytes at day 7 was also $3 \%$ higher than from untreated oocytes $(P<0.05$; Table 1$)$.

\section{bOF increases the quality of in vitro produced blastocysts}

The morphological classification of the blastocysts produced in vitro yielded similar proportions of grade 1 , grade 2, and 'other' (grade 3 and 4) blastocysts from bOF-treated and untreated oocytes (Table 2). Furthermore, in a preliminary experiment, it was shown that the stereomicroscopic appearance of the blastocysts, used to classify them as either grade 1,2, 3 or 4, corresponded with their total cell number; e.g. grade 1 blastocysts, observed using an epifluorescence microscope, had a greater total cell number than grade 3 blastocysts (Fig. 2). Interestingly, the mean total cell number of grade 3 and 4 blastocysts obtained from the bOF-treated oocytes was higher $(P<0.05)$ than from the untreated oocytes group (31.4 \pm 7.9 vs $25.3 \pm 4.2$ respectively).

\section{Oviductal fluid affects the mtDNA transcription/ replication factor and apoptotic gene expression of porcine blastocysts produced in vitro}

In this study, we analyzed the transcript abundance of several developmentally important genes related to apoptosis (BAX and BCL2L1), blastomere connection and morula compaction (GJA1), blastocyst formation and pluripotency (POU5F1), and mtDNA transcription and replication (POLG, POLG2, and TFAM). Grade 1 blastocysts had a greater abundance of the anti-apoptotic BCL2L1 transcripts and also POLG, POLG2, TFAM, GJA1, and POU5F1 transcripts, and a lower abundance of the pre-apoptotic $B A X$ transcripts than grade 2 embryos (Fig. 3). Pre-incubating oocytes with bOF had no effect on the transcript abundance of any of the genes analyzed in

Table 1 Effect of incubating porcine oocytes in bovine oviductal fluid (bOF) on the percentage (mean \pm s.E.M.) of cleaved embryos and blastocysts formed.

\begin{tabular}{|c|c|c|c|}
\hline Group & $N$ & $\begin{array}{l}\text { Percentage of } \\
2-4 \text { cells }\end{array}$ & $\begin{array}{c}\text { Percentage of } \\
\text { blastocysts }^{\text {a }}(N)\end{array}$ \\
\hline $\begin{array}{l}\text { Control } \\
\text { bOF }^{\mathrm{b}}\end{array}$ & $\begin{array}{l}381 \\
338\end{array}$ & $\begin{array}{l}53.2 \pm 2.3^{*} \\
63.6 \pm 2.6^{+}\end{array}$ & $\begin{array}{l}12.8 \pm 1.3^{*}(26) \\
15.8 \pm 1.5^{+}(34)\end{array}$ \\
\hline
\end{tabular}

${ }^{*}{ }^{\dagger}$ Different superscripts in the same column denote significant differences $(P<0.05)$.

${ }^{a}$ From the cleaved embryos. ${ }^{b}$ bOF, oocytes were incubated for $30 \mathrm{~min}$ in bOF after IVM but before IVF.
Table 2 Effect of incubating porcine oocytes in bovine oviductal fluid (bOF) on the morphological classification of in vitro produced blastocysts.

\begin{tabular}{llll}
\hline Group $(N)$ & \multicolumn{1}{c}{ Grade 1 $(\%)$} & \multicolumn{1}{c}{ Grade 2 $(\%)$} & Others $(\%)$ \\
\hline Control $(50)$ & 36.00 & 38.00 & 26.00 \\
bOF $^{\mathrm{a}}(47)$ & 40.41 & 36.17 & 23.42 \\
ANOVA & $P=0.66$ & $P=0.85$ & $P=0.77$
\end{tabular}

abOF, oocytes were incubated for $30 \mathrm{~min}$ in bOF after IVM but before IVF.

grade 1 embryos. However, the ratio between $B A X$ and $B C L 2 L 1$ transcripts was lower $(P<0.05)$, and TFAM transcript abundance was higher $(P<0.05)$ in grade 2 embryos obtained from oocytes pre-incubated with bOF than from oocytes incubated without bOF (Fig. 3).

\section{Discussion}

Previous experiments in our laboratory have shown that pre-incubating porcine oocytes for a very short period (30 min) with bOF and then co-incubating the sperm and oocytes for $18 \mathrm{~h}$ modifies sperm-egg interactions (Coy et al. 2008a). In the present study, we show that a similar methodological approach but with a much shorter (15 min) sperm-oocyte co-incubation period following bOF treatment, to avoid any effects of polyspermy, enhances embryo cleavage rates and the proportion of blastocysts produced. Not only this, it also improves the
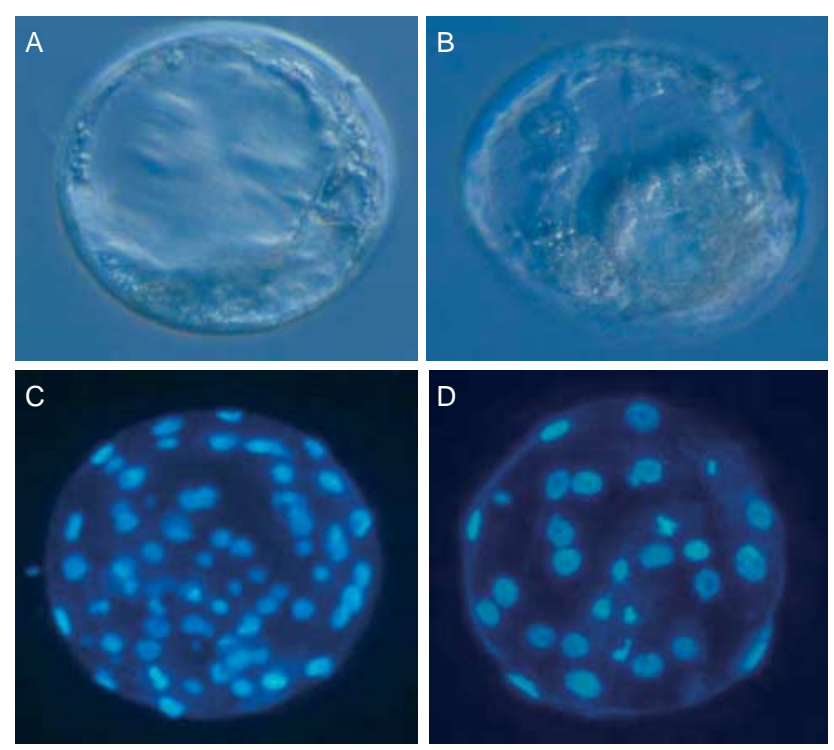

Figure 2 (A) Porcine blastocyst at day 7 observed under the stereomicroscope and classified as grade 1. (B) Porcine blastocyst at day 7 observed under the stereomicroscope and classified as grade 3 . (C) Porcine blastocyst at day 7 stained with Hoechst 33342, fixed, observed under the epifluorescence microscope, and classified as grade 1. (D) Porcine blastocyst at day 7 stained with Hoechst 33342, fixed, observed under the epifluorescence microscope, and classified as grade 3 . 


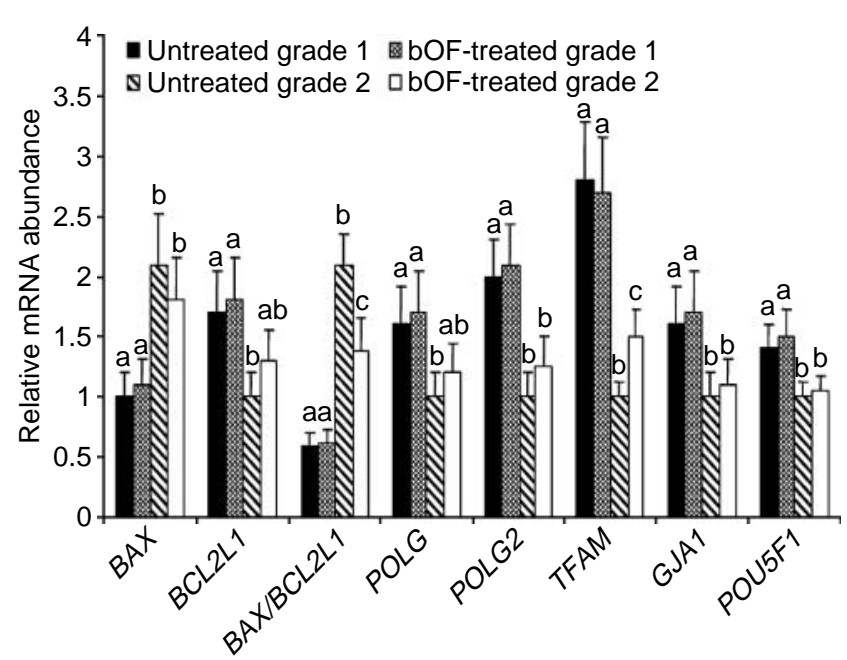

Figure 3 Relative mRNA expression of seven different genes in grade 1 and grade 2 porcine blastocysts produced from oocytes incubated for $30 \mathrm{~min}$ in bovine oviductal fluid (bOF) after IVM but before IVF, or not treated with bOF. Different letters $(a, b)$ in each gene denote significant differences $(P<0.05)$ among groups.

total number of cells observed in grade 3 and 4 blastocysts, and alters the expression of certain developmentally important genes involved with regulating mtDNA transcription/replication (TFAM) and apoptosis (BAX and $B C L 2 L 1)$ in grade 2 blastocysts.

Blastocyst development rates in vitro in the pig are variable, ranging from $6-7 \%$ to $30 \%$ (Nagai et al. 2006). Our final percentages of blastocysts produced for the two groups (bOF treated and untreated) were mid-range ( $\sim 12-16 \%$ respectively), based on the estimates above. Nonetheless, our data demonstrate that the bOF treatment of oocytes has a beneficial effect on the final proportion of blastocysts produced because, even coming from a $3.5 \%$ difference of the final efficiency in the IVF system (Supplementary Table 2), the bOF-treated group reached a $3 \%$ of increase in the final number of blastocysts.

In a preliminary experiment, the stereomicroscopic appearance used to classify the porcine blastocysts into morphological grades corresponded to the total number of cells per blastocyst observed using an epifluorescence microscope. It has been recently shown that stereomicroscopic evaluation of porcine blastocysts is correlated with ultrastructural alterations and cell death (Cuello et al. 2007). This observation, along with previous observations that blastocysts with greater total cell numbers often result in higher pregnancy and birth rates than those with lower total cell numbers (Merton 2002), suggests that our grade 1 blastocysts were of better quality than our grade 3 blastocysts (because the former contained more cells than the latter), and that bOF treatment stimulated cleavage and the production of blastocysts with higher number of cells than in the control group for grade 3 and 4 blastocysts.
The transcript abundance of seven developmentally important genes was also differentially expressed between our grade 1 and 2 blastocysts. Specifically, our grade 1 blastocysts expressed greater levels of GJA1, POU5F1, POLG, POLG2 and TFAM transcripts and a greater ratio of $B C L 2 L 1$ to $B A X$ transcripts than our grade 2 blastocysts. Both GJA1 and POU5F1 transcripts are more abundantly expressed in in vivo than in vitro produced bovine embryos (Rizos et al. 2002, 2007, Gutierrez-Adan et al. 2004). Moreover, in mice, blastocysts with fewer cells exhibit incorrect expression of Pou5f1 and have lower rates of foetal and postnatal development (Boiani et al. 2003).

POLG, POLG2, and TFAM are nuclear-encoded mtDNA-specific transcription and replication factors. TFAM is involved with the initiation of mtDNA replication and transcription (Fisher \& Clayton 1985), whereas POLG is involved with the polymerization of new $\mathrm{mtDNA}$, a process that is assisted by POLG2 (Gray $\&$ Wong 1992). As already mentioned in the introduction, disrupting Polg and Tfam gene expression, e.g. by knocking out the genes in mouse embryos, results in embryonic lethality soon after implantation (Larsson et al. 1998, Hance et al. 2005).

$B C L 2 L 1$ and $B A X$ are anti- and pro-apoptotic regulatory genes respectively. Increased incidence of apoptosis could result in early embryonic death or early abortions (Brill et al. 1999). The ratio of $B C L 2 L 1$ to $B A X$ is proposed to govern whether cells live or die (Oltvai et al. 1993). Characteristically, BCL2L1 transcripts (Rho et al. 2007) are more abundantly expressed than $B A X$ transcripts (Rizos et al. 2002, Gutierrez-Adan et al. 2004, Rho et al. 2007) in in vivo rather than in vitro produced embryos. The functional importance of these genes during embryo development in conjunction with the fact that several of the genes (GJA1, POU5F1, BCL2L1 and BAX) are differentially expressed between in vitro and in vivo produced embryos (which are generally accepted to differ in their developmental potential) suggest strongly that our grade 1 are of better quality than our grade 2 embryos, which in turn further substantiates the suitability of the morphological classification system used in this study.

The most important and interesting findings in the present study were the beneficial effects of treating matured porcine oocytes with bOF for a short period (30 min) prior to fertilization on embryo cleavage and blastocyst development rates, on the total cell numbers (grade 3 and 4 blastocysts), as explained above, and on the gene expression (grade 2 blastocysts). In our opinion, it is possible that the higher quality embryos (grade 1) are more resistant to the stresses imposed by the IVC conditions than the lower quality embryos (grade 2). Thus, the protective effect of bOF only manifests in grade 2 embryos.

The embryo output in the porcine IVM/IVF/IVC system is still very low (Nagai et al. 2006), and this 
simple and novel approach could be widely used in laboratories to increase the output of the system. The mediators responsible for positive effects of the oviductal environment on early embryonic development remain a fundamental question in reproductive biology. The OF has numerous components, including ions, nutrients, amino acids, hormones and proteins (Leese et al. 2001), and deciphering which of these is the active component within bOF responsible for the beneficial effects observed in the present study will not be an easy task. Supplementing culture media with proteins is known to play a crucial role in influencing the efficiency of in vitro embryo production systems (Warzych et al. 2007), but in such a complex milieu as the OF none of the components should be underestimated.

Although it was not the objective of this study to isolate and identify the factor(s) responsible of the beneficial effect, it has to be mentioned that the OF used in the present study was of bovine origin. Not only this, it exerted its effect on the porcine oocytes within a very short $(30 \mathrm{~min})$ period of time. Consequently, the active component within the bOF is most likely to be a conserved protein that is capable of binding to or traversing the ZP and ooplasm within $30 \mathrm{~min}$. OVGP1 appears to fit both of these criteria; its nucleotide and amino acid sequences are highly conserved among mammalian species (Buhi 2002) and it is clearly capable of being transferred from the bOF to the ZP of the porcine oocytes within $30 \mathrm{~min}$ (Fig. 1). Moreover, it has been shown to increase embryo development rates in the porcine previously (Kouba et al. 2000, McCauley et al. 2003), and it is a component of OF (Leese et al. 2001). In this regard, perhaps C3 is also a likely candidate. C3 is also a component of OF, which when activated is cleaved to produce $\mathrm{C} 3 \mathrm{~b}$, and then $\mathrm{iC} 3 \mathrm{~b}$, which has known embryotrophic activity in the mouse (Lee et al. 2004). It is interesting to note that specific nuclear receptors for these factors (that act as transcription factors) could exist and be similar to those for the steroids. One attractive hypothesis might be that these factors traverse the oocyte membrane and interact with their receptors, which then elicit an effect on the expression of certain genes and consequently embryo development.

Alternatively, the active component within bOF could be a protein that protects the embryos produced against disrupted mtDNA transcription/replication and/or apoptosis induced by the culture environment. We infer this on the basis of TFAM transcripts being more abundant and the ratio of BCL2L1 to BAX transcripts, being greater in our grade 2 blastocysts derived from bOF-treated oocytes rather than from untreated oocytes. As mentioned earlier, TFAM is essential for mtDNA transcription/replication, which in turn is essential for development. This is best illustrated by Tfam knockout mouse embryos that die soon after implantation due to severe mtDNA depletion, mitochondrial respiratory chain dysfunction, and morphologically abnormal mitochondria (Larsson et al. 1998). In light of this information, it is possible that our grade 2 blastocysts obtained from untreated oocytes have less developmental potential than those obtained bOF-treated oocytes because they have lower TFAM transcript abundance and, assuming the transcript levels mirror protein levels, this in turn could reflect lower rates of mtDNA transcription/replication, fewer mtDNAencoded transcripts, and therefore fewer functional subunits for the mitochondrial respiratory chain. This hypothesis should be further investigated but it is not unusual for genes that are involved with maintaining the integrity of the mitochondrial respiratory chain (e.g. $A T P 5 B$ and $C O X 7 B)$ to be downregulated in poor quality blastocysts compared with good quality blastocysts in the pig (Miles et al. 2008).

Interestingly, the fact that our grade 2 blastocysts obtained from untreated oocytes exhibit an apoptotic gene expression-like profile relative to our grade 2 blastocysts obtained from bOF-treated oocytes could in fact be related to the differences in TFAM transcript abundance observed between the two blastocyst groups. Apoptosis is incredibly prevalent in mouse Tfam knockout embryos, suggesting that a dysfunctional mitochondrial respiratory chain can cause apoptosis (Wang et al. 2001). It is unclear what factor within bOF could maintain the enhanced TFAM transcript abundance and the similarly enhanced ratio of $B C L 2 L 1$ to $B A X$ transcripts observed in our grade 2 blastocyst obtained from bOF-treated oocytes relative to untreated oocytes.

However, embryos produce more reactive oxygen species (ROS) in vitro than in vivo (Guerin et al. 2001), and it is generally accepted that ROS are capable of inducing apoptosis, although it is not known how (Rho et al. 2007). It is possible that an enzyme like thioredoxin (TXN), shown to be upregulated in OF in response to the presence of gametes in situ and known to alleviate oxidative stress by breaking down ROS like $\mathrm{H}_{2} \mathrm{O}_{2}$ to harmless $\mathrm{H}_{2} \mathrm{O}$ (Georgiou et al. 2005), is the active component within the bOF responsible for the enhanced ratio of $B C L 2 L 1$ to $B A X$ transcripts observed in our grade 2 blastocyst obtained from bOF-treated oocytes relative to untreated oocytes.

Alternatively, the beneficial effect of the bOF treatment on our grade 2 embryos could be mediated by sperm selection. Previously, we have shown that bOF treatment increases the resistance of ZP to proteolysis (Coy et al. 2008a). Consequently, we hypothesized that only the 'stronger' sperm, possibly with 'better' genes, can cross the ZP. Thus, if our hypothesis is correct, our grade 2 embryos derived from bOF-treated oocytes would have been fertilized by better sperm than those derived from untreated oocytes. This in turn could also account for the differences in gene expression observed 
between the two embryo groups. The fact that transcription, although very limited, which is more prominent in the male pronucleus than in the female pronucleus at the zygote stage (Beaujean et al. 2000), would tend to support this view.

In conclusion, the bOF is capable of providing porcine oocytes with components over a very short period of time between IVM and IVF, which benefit embryo development and embryo quality. The challenge is now to identify this (these) embryotrophic component(s), and then to add it (them) to porcine IVC systems to improve their output.

\section{Materials and Methods}

\section{Culture media}

Unless otherwise indicated, all chemicals and reagents were purchased from Sigma-Aldrich Química S.A. The medium used for oocyte maturation was NCSU-37 and the basic medium used for IVF was TALP supplemented as described previously (Coy et al. 2008b). The embryo culture medium was NCSU-23 (Long et al. 1999).

\section{Oocyte collection and IVM}

Within 30 min of slaughter, ovaries from landrace $\times$ large white gilts were transported to the laboratory in saline containing $100 \mu \mathrm{g} / \mathrm{ml}$ kanamycin sulfate at $38^{\circ} \mathrm{C}$, washed once in $0.04 \%$ cetrimide solution and twice in saline. Oocyte-cumulus cell complexes (COCs) were collected from antral follicles (3-6 mm diameter), washed twice with Dulbecco's PBS supplemented with $1 \mathrm{mg} / \mathrm{ml}$ polyvinyl alcohol (PVA) and $0.005 \mathrm{mg} / \mathrm{ml}$ red phenol, and twice more in maturation medium previously equilibrated for a minimum of $3 \mathrm{~h}$, at $38.5{ }^{\circ} \mathrm{C}$ under $5 \% \mathrm{CO}_{2}$ in air. Only COCs with complete and dense cumulus oophorus were used for the experiments. Groups of 50 COCs were cultured in $500 \mu \mathrm{l}$ maturation medium for $22 \mathrm{~h}$ at $38.5^{\circ} \mathrm{C}$ under $5 \% \mathrm{CO}_{2}$ in air. After culture, oocytes were washed twice with fresh maturation medium without dibutyryl cAMP, eCG, and hCG and cultured for an additional 20-22 h (Funahashi et al. 1997).

\section{Collection of oviductal fluid}

Oviducts were obtained at the abattoir and transported in saline to the laboratory at room temperature. All the oviducts came from heifers between 14 and 20 months old, and only those coming from animals at the late follicular phase were used because it has been demonstrated that this type of fluid consistently shows beneficial effects on porcine IVF (Coy et al. 2008a). Oviducts were washed twice, transferred to Petri dishes on an ice bath and dissected. bOF was collected by aspiration with an automatic pipette using a tip for a maximum $200 \mu \mathrm{l}$ volume and centrifuged at $7000 \mathrm{~g}$ for $10 \mathrm{~min}$ at $4{ }^{\circ} \mathrm{C}$ to remove cellular debris (Carrasco et al. 2008). The supernatant was stored at $-80^{\circ} \mathrm{C}$ until use.

\section{Treatment of pig IVM oocytes with bOF and demonstration of heterologous binding for bovine oviduct-specific glycoprotein to porcine ZP}

After IVM but before IVF, porcine oocytes were gently stripped of cumulus cells and incubated in bOF ( 1 oocyte/ $\mu$ l fluid) in groups of $10-30$ oocytes for $30 \mathrm{~min}$ at $38.5{ }^{\circ} \mathrm{C}$ under $5 \% \mathrm{CO}_{2}$ in air. Oocytes were washed three times and transferred to fresh TALP medium. A control group of oocytes incubated in TALP medium, instead of bOF, under the same conditions as above was used in all experiments.

A polyclonal antibody produced in rabbit (Sigma Genosys) against bovine OVGP1 was used to check the binding of bovine OVGP1 to porcine ZP. First, porcine oocytes were incubated in bOF as explained above, second, with a primary antibody antiOVGP1 IgG, and finally, with a secondary goat peroxidaselabelled anti-rabbit antibody (Santa Cruz Biotechnology, Santa Cruz, CA, USA). After washing, peroxidase activity was detected using 3,3'-diaminobenzidine as chromogen with $\mathrm{H}_{2} \mathrm{O}_{2}$ substrate to observe the staining around ZP.

\section{IVF and embryo production}

After bOF treatment, groups of 30-35 partially denuded oocytes were transferred into each well of a four-well multidish containing $250 \mu \mathrm{l}$ of TALP medium pre-equilibrated at $38.5^{\circ} \mathrm{C}$ under $5 \% \mathrm{CO}_{2}$. Following this, a sperm-rich fraction of semen from a mature, fertility tested boar, was collected by the gloved hand method and rapidly brought to the laboratory diluted 1:1 in Beltsville thawing solution (Pursel \& Johnson 1975). Aliquots of the semen samples $(0.5 \mathrm{ml})$ were centrifuged $(700 \mathrm{~g}$, $30 \mathrm{~min})$ through a discontinuous Percoll (Pharmacia) gradient (45 and $90 \% \mathrm{v} / \mathrm{v})$, and the resultant sperm pellets were diluted in TALP medium and centrifuged again for $10 \mathrm{~min}$ at $100 \mathrm{~g}$. Finally, the pellet was diluted in TALP, and $250 \mu$ l of the suspension was added to wells with oocytes to a final content of $10^{5}$ cells $/ \mathrm{ml}$. At 15 min post-insemination, oocytes were washed twice with fresh TALP by gentle aspiration through a glass pipette and allowed to continue in culture. At $3 \mathrm{~h}$ post-insemination (hpi), putative zygotes were transferred to NCSU-23 medium and allowed to develop for 7 days.

\section{Assessment of embryo quality}

Embryo quality for both control and experimental groups was assessed by (i) morphological classification of the day 7 blastocysts under the stereomicroscope, (ii) Hoechst staining and counting of cell number in each blastocyst, and (iii) measuring the level of seven selected gene transcripts by real-time RT-PCR.

(i) All of the blastocysts produced were morphologically classified using a stereomicroscope as either grade 1, grade 2, grade 3 , or grade 4 in accordance with the criteria set out in the IETS Manual (Robertson \& Nelson 1998) for bovine blastocysts.

(ii) After morphological classification, all the grade 3 and grade 4 embryos were processed for cell counting. The total number of cells per blastocyst was recorded under an epifluorescence microscope for each individual sample after 
dry air fixation on a slide and Hoechst staining (1\% Hoechst 33342 in PBS).

(iii) Additionally, after morphological classification, all grade 1 and grade 2 embryos were processed for real-time RT-PCR. Indeed, individual blastocysts were collected into $5 \mu \mathrm{l}$ of PBS supplemented with $0.1 \%$ PVA and stored at $-80{ }^{\circ} \mathrm{C}$ for this purpose. It seemed logical to just include grade 1 and 2 blastocysts in the real-time RT-PCR assays because, typically, only these grade 1 and 2 blastocysts are used for embryo transfers commercially, at least in cattle. The quality of grade 3 and 4 embryos is too poor to be used for developmental purposes.

Furthermore, in a preliminary experiment, a sample of embryos was taken and the total numbers of cells in grade 1 and 2 blastocysts was compared with that of grade 3 and 4 blastocysts, as described above.

\section{Real time RT-PCR analysis of embryos}

Forty blastocysts from each treatment group (bOF-treated and untreated oocytes) were analyzed by real-time RT-PCR. RNA was extracted from blastocysts in pools of six to eight using an RNAqueous-Micro RNA Isolation kit (Ambion, Austin, TX, USA), according to the manufacturer's instructions. RNA was incubated with DNasel to ensure the removal of contaminating DNA. RNA extracted from embryos was reverse transcribed to produce cDNA using the ABsolute MAX 2-Step QRT-PCR kit (Abgene, Epsom, UK). Briefly, each reaction contained $6.5 \mu \mathrm{l}$ RNA, $4 \mu$ l RT buffer (5X), $2 \mu \mathrm{l}$ dNTPs ( $5 \mathrm{mM}$ each), $1 \mu$ l oligodT primer $(500 \mathrm{ng} / \mathrm{ml}), 1 \mu \mathrm{l}$ RT enhancer, $1 \mu \mathrm{l}$ Reverse-iTTM MAX RTase Blend (which includes an RNase inhibitor; Abgene, Surrey, UK), and made up to a total volume of $20 \mu \mathrm{l}$ using sterile $\mathrm{dd}_{2} \mathrm{O}$. Additionally, parallel reactions containing all the components above, with the exception of the enzyme (no enzyme control), were set up to screen each RNA sample for the presence of contaminating DNA. Furthermore, a reaction containing all the reagents above, but no RNA (no template control) was set up to screen the reagents for contaminants. The reactions were carried out at $42{ }^{\circ} \mathrm{C}$ for $1 \mathrm{~h}$, followed by $75{ }^{\circ} \mathrm{C}$ for 10 min using a GeneAmp PCR system 9700 (Applied
Biosystems, Foster City, CA, USA). The resulting cDNA was then diluted $1: 5$ in sterile $\mathrm{ddH}_{2} \mathrm{O}$ and either analyzed immediately or stored at $-20{ }^{\circ} \mathrm{C}$ until use. Real time RT-PCR was performed on each cDNA sample using a Rotorgene 2000 Real Time CyclerTM (Corbett Research, Sydney, Australia) and SYBR Green (Molecular Probes, Eurogene, OR, USA). Each reaction contained: $2 \mu \mathrm{l}$ CDNA, $1 \mathrm{X}$ PCR buffer, $3 \mathrm{mM} \mathrm{MgCl}$, $2 \cup$ Taq Express (MWGAG Biotech, Ebersberg, Germany), $100 \mathrm{mM}$ of each dNTPs, and $0.2 \mathrm{mM}$ of each forward and reverse primer (see Table 3 for primer sequences) and SYBR Green I (diluted 1:3000, from a $10000 \mathrm{X}$ stock solution), and each reaction was made up to a total volume of $25 \mu \mathrm{l}$ using sterile $\mathrm{ddH}_{2} \mathrm{O}$. Each reaction had an initial denaturation step at $94{ }^{\circ} \mathrm{C}$ for $2 \mathrm{~min}$, followed by 40 cycles of denaturation at $94{ }^{\circ} \mathrm{C}$ for $15 \mathrm{~s}$, annealing at the appropriate temperature for the primers (Table 3) for $30 \mathrm{~s}$ and elongation at $72{ }^{\circ} \mathrm{C}$ for $10 \mathrm{~s}$. Fluorescence data were acquired at $72-83{ }^{\circ} \mathrm{C}$ after the elongation step. At the end of a reaction, the PCR products were melted by ramping from 50 to $94{ }^{\circ} \mathrm{C}$, holding for $5 \mathrm{~s}$ and acquiring fluorescence data at each step. Each cDNA sample was analyzed by real-time RT-PCR in triplicate. Product identity was confirmed by ethidium bromide-stained $2 \%$ agarose gel electrophoresis (see Table 3 for expected product sizes from each primer pair). The comparative $C_{\mathrm{t}}$ method was used to determine the transcript levels of $B A X, B C L 2 L 1, G J A 1$, POU5F1, POLG, POLG2 and TFAM, i.e., the so-called target genes, relative to glyceraldehyde-3-phosphate dehydrogenase $(G A P D H)$ transcript levels in each sample, as described previously (Bermejo-Alvarez et al. 2008). GAPDH was chosen as a normalizer gene as its transcript levels have been shown to be unchanged between IVF and in vivo derived blastocysts (Kameyama et al. 2007). Briefly, fluorescence data were acquired in each cycle to determine the threshold cycle or the cycle during the log-linear phase of the reaction, at which fluorescence increased above background for each sample. Within this region of the amplification curve, a difference of one cycle is equivalent to doubling of the amplified PCR product. According to the comparative $C_{\mathrm{t}}$ method, the $\Delta C_{\mathrm{t}}$ value was determined by subtracting the GAPDH $C_{\mathrm{t}}$ value for each sample from the target gene $C_{\mathrm{t}}$ value of the sample.

Table 3 Details of primers used for quantitative real-time RT-PCR.

\begin{tabular}{|c|c|c|c|c|}
\hline $\begin{array}{l}\text { Gene } \\
\text { symbol }\end{array}$ & NCBI official name & Primers sequence $\left(5^{\prime}-3^{\prime}\right)$ & $\begin{array}{l}\text { Fragment } \\
\text { size }\end{array}$ & $\begin{array}{l}\text { GenBank } \\
\text { accession number }\end{array}$ \\
\hline$B A X$ & BCL2-associated X protein & $\begin{array}{l}\text { 5'-CTACTTTGCCAGTAAACTGG } \\
\text { 5'-TCCCAAAGTAGGAGAGGA }\end{array}$ & 158 & AJ606301.1 \\
\hline$B C L 2 L 1$ & BCL2-like 1 & $\begin{array}{l}\text { 5'-GGAGCTGGTGGTTGACTTTC } \\
5^{\prime} \text {-CTAGGTGGTCATTCAGGTAAG }\end{array}$ & 518 & AF216205 \\
\hline POLG & Mitochondrial polymerase gamma & $\begin{array}{l}5^{\prime} \text {-ACTGGCTGGACATCAGCAGT } \\
5^{\prime} \text {-GACAGTACTGCATCAGGTCC }\end{array}$ & 194 & AK291281.1 \\
\hline POLG2 & Mitochondrial polymerase gamma 2 & $\begin{array}{l}\text { 5'-GCCTTGGAGCATTATGTT } \\
5^{\prime} \text {-GAAGCTTCAGTCTTTTCACCG }\end{array}$ & 148 & AK235352 \\
\hline TFAM & Mitochondrial transcription factor A & $\begin{array}{l}\text { 5'-GGCAGACTGGCAGGTGTA } \\
5^{\prime} \text {-CGAGGTCTTTTTGGTTTTCCA }\end{array}$ & 164 & AF311909 \\
\hline GJA1 & Gap junction protein, alpha 1, $43 \mathrm{kDa}$ & $\begin{array}{l}5^{\prime} \text {-TGCCTTTCGTTGTAACACTCA } \\
5^{\prime} \text {-AGAACACATGAGCCAGGTACA }\end{array}$ & 142 & AY382593.1 \\
\hline POU5F1 & POU class 5 homeobox 1 & $\begin{array}{l}5^{\prime} \text {-TTGGGCTAGAGAAGGATGTGGTT } \\
5^{\prime} \text {-GGAAAAGGGACTGAGTAGAGTGTGG }\end{array}$ & 364 & NM001113060.1 \\
\hline GAPDH & Glyceraldehyde-3-phosphate dehydrogenase & $\begin{array}{l}\text { 5'-ACCCAGAAGACTGTGGATGG } \\
5^{\prime} \text {-ACGCCTGCTTCACCACCTTC }\end{array}$ & 247 & BC102589 \\
\hline
\end{tabular}


Calculation of $\Delta \Delta C_{\mathrm{t}}$ involved using the highest sample $\Delta C_{\mathrm{t}}$ value (i.e., the sample with the lowest target gene expression) as an arbitrary constant to subtract from all other $\Delta C_{\mathrm{t}}$ sample values. Fold changes in the transcript levels of the target genes aforementioned relative to GAPDH transcript levels were then determined using the formula $2^{-\Delta \Delta C_{\mathrm{t}}}$.

\section{Statistical analysis}

The percentage of cleaved embryos, blastocysts formed and the mean number of cells per blastocyst are presented as the mean \pm S.E.M. All percentages were modeled according to the binomial model of variables. The variables were analyzed by one-way ANOVA. A $P$ value $<0.05$ was taken to denote statistical significance. One-way repeated-measures ANOVA (followed by multiple pair-wise comparisons using StudentNewman-Kleus method) was used for the analysis of differences in mRNA expression assayed by real-time RT-PCR.

\section{Declaration of interest}

There is no conflict of interest that could be perceived as prejudicing the impartiality of the research reported.

\section{Funding}

This work was supported by the Spanish Ministry of Education and Science and FEDER (grant numbers AGL2006-03495 and AGL2006-04799). P C's stay in London was supported by the Spanish Ministry of Education (grant no. PR2006-0506).

\section{Acknowledgements}

The authors would like to thank Manuel Avilés and Irene Mondéjar for their help with the immunocytochemical analysis.

\section{References}

Beaujean N, Bouniol-Baly C, Monod C, Kissa K, Jullien D, Aulner N, Amirand C, Debey P \& Kas E 2000 Induction of early transcription in one-cell mouse embryos by microinjection of the nonhistone chromosomal protein HMG-I. Developmental Biology 221 337-354.

Bermejo-Alvarez P, Rizos D, Rath D, Lonergan P \& Gutierrez-Adan A 2008 Epigenetic differences between male and female bovine blastocysts produced in vitro. Physiological Genomics 32 264-272.

Boiani M, Eckardt S, Leu NA, Scholer HR \& McLaughlin KJ 2003 Pluripotency deficit in clones overcome by clone-clone aggregation: epigenetic complementation? EMBO Journal 22 5304-5312.

Brill A, Torchinsky A, Carp H \& Toder V 1999 The role of apoptosis in normal and abnormal embryonic development. Journal of Assisted Reproduction and Genetics 16 512-519.

Buhi WC 2002 Characterization and biological roles of oviduct-specific, oestrogen-dependent glycoprotein. Reproduction 123 355-362.

Carrasco LC, Romar R, Aviles M, Gadea J \& Coy P 2008 Determination of glycosidase activity in porcine oviductal fluid at the different phases of the estrous cycle. Reproduction 136 833-842.

Coy P, Martinez E, Ruiz S, Vazquez JM, Roca J \& Matas C 1993 Sperm concentration influences fertilization and male pronuclear formation in vitro in pigs. Theriogenology 40 539-546.
Coy P, Canovas S, Mondéjar I, Romar R, Saavedra MD, Grullon L, Matas C \& Aviles M 2008a Oviduct-specific glycoprotein and heparin modulate sperm-zona pellucida interaction during fertilization and regulate polyspermy. PNAS 105 15809-15814.

Coy P, Grullon L, Canovas S, Romar R, Matas C \& Aviles M $2008 b$ Hardening of the zona pellucida of unfertilized eggs can reduce polyspermic fertilization in the pig and cow. Reproduction 135 19-27.

Cuello C, Berthelot F, Delaleu B, Venturi E, Pastor LM, Vazquez JM, Roca J, Martinat-Botte F \& Martinez EA 2007 The effectiveness of the stereomicroscopic evaluation of embryo quality in vitrified-warmed porcine blastocysts: an ultrastructural and cell death study. Theriogenology 67 970-982.

Fernandez-Gonzalez R, Moreira P, Bilbao A, Jimenez A, Perez-Crespo $M$, Ramirez MA, Rodriguez De Fonseca F, Pintado B \& Gutierrez-Adan A 2004 Long-term effect of in vitro culture of mouse embryos with serum on mRNA expression of imprinting genes, development, and behavior. PNAS 101 5880-5885.

Fisher RP \& Clayton DA 1985 A transcription factor required for promoter recognition by human mitochondrial RNA polymerase. Accurate initiation at the heavy- and light-strand promoters dissected and reconstituted in vitro. Journal of Biological Chemistry $26011330-11338$.

Funahashi H, Cantley TC \& Day BN 1997 Synchronization of meiosis in porcine oocytes by exposure to dibutyryl cyclic adenosine monophosphate improves developmental competence following in vitro fertilization. Biology of Reproduction 57 49-53.

Georgiou AS, Sostaric E, Wong CH, Snijders AP, Wright PC, Moore HD \& Fazeli A 2005 Gametes alter the oviductal secretory proteome. Molecular and Cellular Proteomics 4 1785-1796.

Giritharan G, Talbi S, Donjacour A, Di Sebastiano F, Dobson AT \& Rinaudo PF 2007 Effect of in vitro fertilization on gene expression and development of mouse preimplantation embryos. Reproduction 134 63-72.

Gray H \& Wong TW 1992 Purification and identification of subunit structure of the human mitochondrial DNA polymerase. Journal of Biological Chemistry 267 5835-5841.

Guerin P, El Mouatassim S \& Menezo Y 2001 Oxidative stress and protection against reactive oxygen species in the pre-implantation embryo and its surroundings. Human Reproduction Update 7 175-189.

Gutierrez-Adan A, Rizos D, Fair T, Moreira PN, Pintado B, de la Fuente J, Boland MP \& Lonergan P 2004 Effect of speed of development on mRNA expression pattern in early bovine embryos cultured in vivo or in vitro. Molecular Reproduction and Development 68 441-448.

Hance N, Ekstrand MI \& Trifunovic A 2005 Mitochondrial DNA polymerase gamma is essential for mammalian embryogenesis. Human Molecular Genetics 14 1775-1783.

Kameyama Y, Filion F, Yoo JG \& Smith LC 2007 Characterization of mitochondrial replication and transcription control during rat early development in vivo and in vitro. Reproduction 133 423-432.

Kouba AJ, Abeydeera LR, Alvarez IM, Day BN \& Buhi WC 2000 Effects of the porcine oviduct-specific glycoprotein on fertilization, polyspermy, and embryonic development in vitro. Biology of Reproduction 63 242-250.

Larsson NG, Wang J, Wilhelmsson H, Oldfors A, Rustin P, Lewandoski M, Barsh GS \& Clayton DA 1998 Mitochondrial transcription factor A is necessary for mtDNA maintenance and embryogenesis in mice. Nature Genetics 18 231-236.

Lee KF \& Yeung WS 2006 Gamete/embryo-oviduct interactions: implications on in vitro culture. Human Fertility 9 137-143.

Lee YL, Lee KF, Xu JS, He QY, Chiu JF, Lee WM, Luk JM \& Yeung WS 2004 The embryotrophic activity of oviductal cell-derived complement C3b and $\mathrm{iC} 3 \mathrm{~b}$, a novel function of complement protein in reproduction. Journal of Biological Chemistry 279 12763-12768.

Leese HJ, Tay JI, Reischl J \& Downing SJ 2001 Formation of fallopian tubal fluid: role of a neglected epithelium. Reproduction 121 339-346.

Lonergan P, Rizos D, Gutierrez-Adan A, Fair T \& Boland MP 2003 Effect of culture environment on embryo quality and gene expression - experience from animal studies. Reproductive Biomedicine Online 7 657-663.

Long CR, Dobrinsky JR \& Johnson LA 1999 In vitro production of pig embryos: comparisons of culture media and boars. Theriogenology $\mathbf{5 1}$ 1375-1390.

McCauley TC, Buhi WC, Wu GM, Mao J, Caamano JN, Didion BA \& Day BN 2003 Oviduct-specific glycoprotein modulates sperm-zona binding and improves efficiency of porcine fertilization in vitro. Biology of Reproduction 69 828-834. 
Merton JS 2002 Morphological evaluation of embryos in domestic species. In Assessment of Mammalian Embryo Quality: Invasive and Non-Invasive Techniques, pp 33-55. Ed. A van Soom. Doordrecht, The Netherlands: Kluwers Academic Publishers.

Miles JR, Blomberg le A, Krisher RL, Everts RE, Sonstegard TS, Van Tassell CP \& Zuelke KA 2008 Comparative transcriptome analysis of in vivo- and in vitro-produced porcine blastocysts by small amplified RNAserial analysis of gene expression (SAR-SAGE). Molecular Reproduction and Development 75 976-988.

Nagai T, Funahashi H, Yoshioka K \& Kikuchi K 2006 Up date of in vitro production of porcine embryos. Frontiers in Bioscience: A Journal and Virtual Library 11 2565-2573.

Oltvai ZN, Milliman CL \& Korsmeyer SJ 1993 Bcl-2 heterodimerizes in vivo with a conserved homolog, Bax, that accelerates programmed cell death. Cell 74 609-619.

Pursel VG \& Johnson LA 1975 Freezing of boar spermatozoa: fertilizing capacity with concentrated semen and a new thawing procedure. Journal of Animal Science 40 99-102.

Rho GJ, S B, Kim DS, Son WJ, Cho SR, Kim JG, B MK \& Choe SY 2007 Influence of in vitro oxygen concentrations on preimplantation embryo development, gene expression and production of Hanwoo calves following embryo transfer. Molecular Reproduction and Development 74 486-496.

Rizos D, Lonergan P, Boland MP, Arroyo-Garcia R, Pintado B, de la Fuente J \& Gutierrez-Adan A 2002 Analysis of differential messenger RNA expression between bovine blastocysts produced in different culture systems: implications for blastocyst quality. Biology of Reproduction $\mathbf{6 6}$ 589-595.
Rizos D, Pintado B, de la Fuente J, Lonergan P \& Gutierrez-Adan A 2007 Development and pattern of mRNA relative abundance of bovine embryos cultured in the isolated mouse oviduct in organ culture. Molecular Reproduction and Development 74 716-723.

Robertson I \& Nelson RE 1998 Certification of the embryos. In Manual of the International Embryo Transfer Society, 3 edn, pp 103-134. Ed. SM Seidel. Savoy, IL: Stringfellow DAS.

De Sousa PA, Juneja SC, Caveney S, Houghton FD, Davies TC, Reaume AG, Rossant J \& Kidder GM 1997 Normal development of preimplantation mouse embryos deficient in gap junctional coupling. Journal of Cell Science 15 1751-1758.

Wang J, Silva JP, Gustafsson CM, Rustin P \& Larsson NG 2001 Increased in vivo apoptosis in cells lacking mitochondrial DNA gene expression. PNAS 98 4038-4043.

Warzych E, Wrenzycki C, Peippo J \& Lechniak D 2007 Maturation medium supplements affect transcript level of apoptosis and cell survival related genes in bovine blastocysts produced in vitro. Molecular Reproduction and Development 74 280-289.

Xu JS, Chan ST, Lee WW, Lee KF \& Yeung WS 2004 Differential growth, cell proliferation, and apoptosis of mouse embryo in various culture media and in coculture. Molecular Reproduction and Development 68 72-80.

Received 1 October 2008

First decision 4 November 2008

Revised manuscript received 29 December 2008

Accepted 19 January 2009 